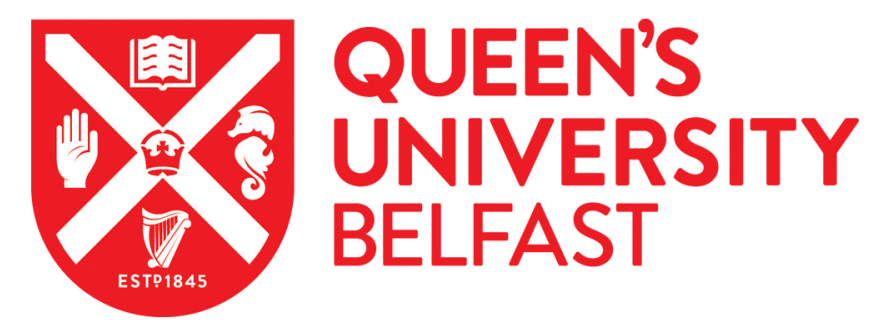

\title{
Numerical Analysis of Thermal Systems of a Bus Engine
}

Karamanos, K., Mahmoudi, Y., Kim, S., \& Best, R. (2019). Numerical Analysis of Thermal Systems of a Bus Engine. In 16th UK Heat Transfer Conference 2019: Proceedings [123] https://doi.org/10.1007/978-981-334765-6_100

\section{Published in:}

16th UK Heat Transfer Conference 2019: Proceedings

\section{Document Version:}

Publisher's PDF, also known as Version of record

\section{Queen's University Belfast - Research Portal:}

Link to publication record in Queen's University Belfast Research Portal

\section{General rights}

Copyright for the publications made accessible via the Queen's University Belfast Research Portal is retained by the author(s) and / or other copyright owners and it is a condition of accessing these publications that users recognise and abide by the legal requirements associated with these rights.

Take down policy

The Research Portal is Queen's institutional repository that provides access to Queen's research output. Every effort has been made to ensure that content in the Research Portal does not infringe any person's rights, or applicable UK laws. If you discover content in the Research Portal that you believe breaches copyright or violates any law, please contact openaccess@qub.ac.uk. 


\title{
NUMERICAL ANALYSIS OF THERMAL SYSTEMS OF A BUS ENGINE
}

\author{
Konstantinos Karamanos $^{1 *}$, Yasser Mahmoudi Larimi ${ }^{1}$, Sung In Kim ${ }^{1}$, Robert Best ${ }^{2}$ \\ ${ }^{1}$ School of Mechanical and Aerospace Engineering, Queen's University Belfast, BT9 5AH, United Kingdom \\ ${ }^{2}$ Wrights Group Ltd, Ballymena, Co., Antrim, BT42 1PY, United Kingdom
}

\section{INTRODUCTION}

Transportation is one of the main sectors contributing to climate change via the production of greenhouse gas emissions. In particular, 27\% of UK emissions are attributed to transport [1]. European Union, in order to tackle this problem, has introduced the Euro VI regulations for heavy-duty vehicles [2]. Vehicle thermal management systems have been a critical part of improving vehicle fuel economy, as more than 50\% of fuel energy is going to heat. Thermal systems are very complex in terms of thermo-fluid analysis due to the different shaped and size of the components, which make experimental testing challenging [3]. Wang et al. [4] developed an integrated (1D/3D) model consisting of three sub-models, an engine cooling system including the oil circuit, a charge-air cooling system and a HVAC system. With this method, both the heat transfer and transient characteristics of the thermal systems can be simulated and analysed. Similarly, Bayraktar [5] used the integrated modelling method to analyse the powertrain and HVAC systems. The results showed that low-order modelling provides a positive first representation of a proposed system, however 3D simulations are required to analyse the system's behaviour at transient state conditions. Bolehovsky et al. [6] compared the 1D and 1D/3D simulations for an engine cooling system. The results showed that the 1D model overestimates the heat transfer rate at radiator by $10 \%$.

\section{METHDOLOGY}

An integrated 0D/3D modelling approach is adopted in this research. A MATLAB based OD model is developed which consists of six sub-models: combustion chamber model, cooling system, charge-air cooling system, lubricant system, EGR cooler and turbocharger (figure 1). All the components placed in the under-hood are modelled using laws of thermodynamics and heat transfer equations. In a bus, the engine bay is at the back in order to maximise the interior space. Radiator and charge-air cooler are at the side of the vehicle and they are exposed to highly transient and turbulent airflow. Therefore, low order modeling approaches cannot resolve property the flow and thermal characteristics of these two elements. Thus, 3D computation is required to model the effect of the external air flow as well as the internal water's cooling flow on the thermal feature of the system. In this regard, to minimise the computational time, two 3D models have been developed. One that simulates the airflow around the bus and one that analyses the heat and fluid flow of radiator and charge-air cooler in the engine bay. The first model establishes the boundary conditions for the engine bay model, which feeds data to the OD model and complete the calculation.

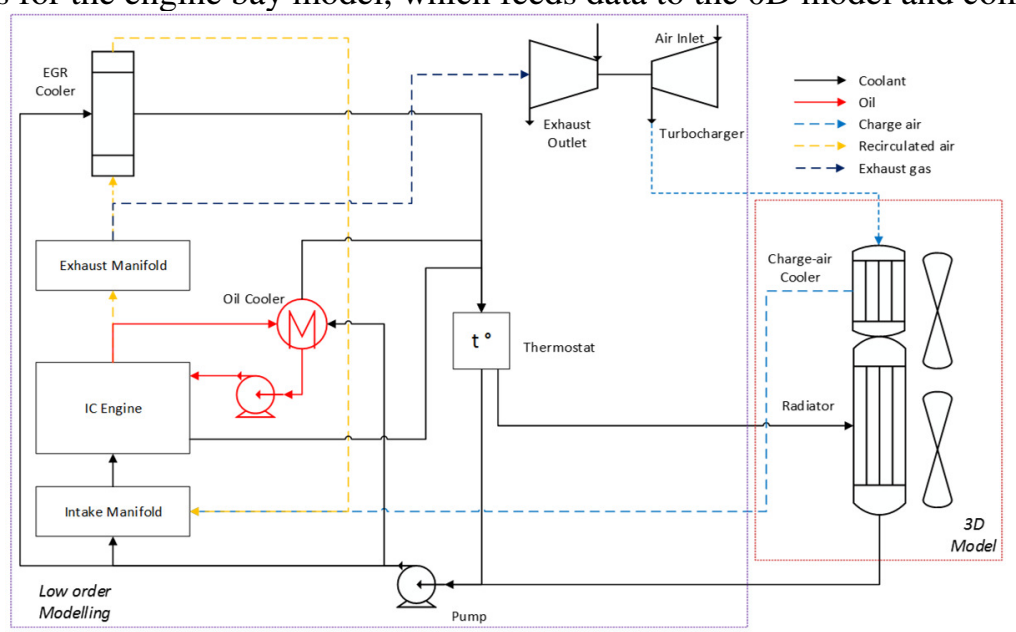

Fig. 1 Schematic diagram of the integrated model

*Corresponding Author: kkaramanos01@qub.ac.uk 


\section{RESULTS}

A closed fluid domain to replicate the wind tunnel was created to generate the airflow features in the engine bay. Figure 2 shows that the airflow captured at the grilles is significantly reduced. This results in lower heat rejection at radiator and charge-air cooler for buses comparing to cars. Thus, the main source of airflow is the fans which cause a transient and non-uniform flow at the downstream of the fans which subsequently go through the fins of the radiator and charge-air cooler (figure 3).

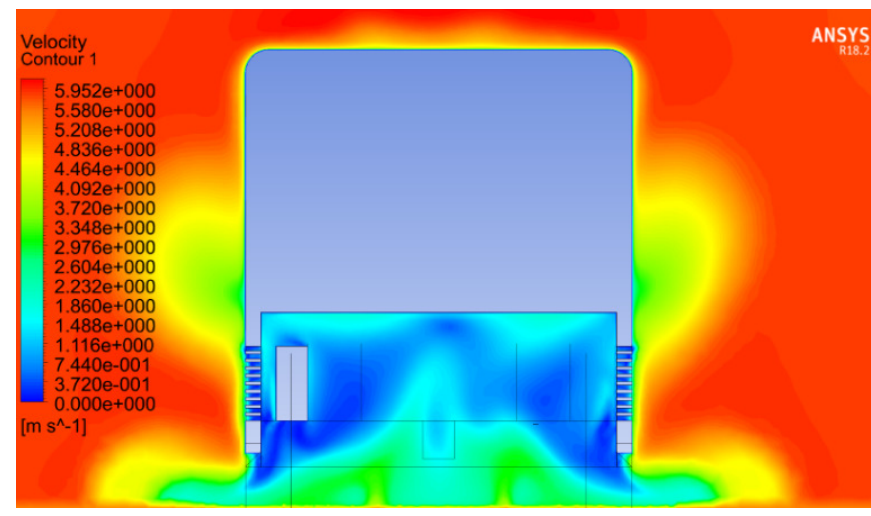

Fig. 2 Air velocity contours at the engine bay

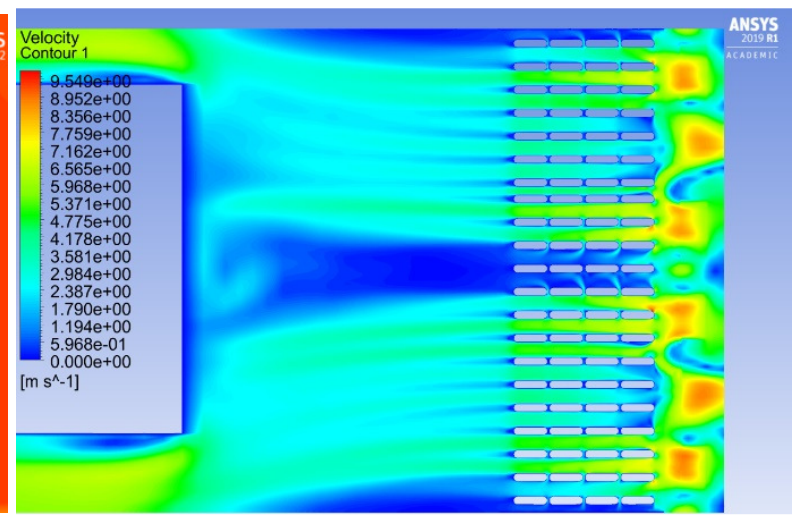

Fig. 3 Air velocity contours between the tubes

A full scale $0 \mathrm{D}$ and a coupled 0D/3D model were tested under the same operating condition based on the MLTB drive cycle. The bus speed was $55 \mathrm{~km} / \mathrm{h}$ and the engine speed and torque were $1500 \mathrm{rpm}$ and $850 \mathrm{Nm}$ respectively. As it is illustrated in figure 4, the heat transfer rate at radiator and charge-air cooler is overestimated. This occurs because the OD model cannot capture accurately the airflow features at the rear of the bus, specifically at the grilles where radiator and charge-air cooler are placed. Therefore, the heat transfer coefficient between the external air and the surface of the components is not precisely estimated. Moreover, the results show that more than $50 \%$ of the heat loss can be recovered.

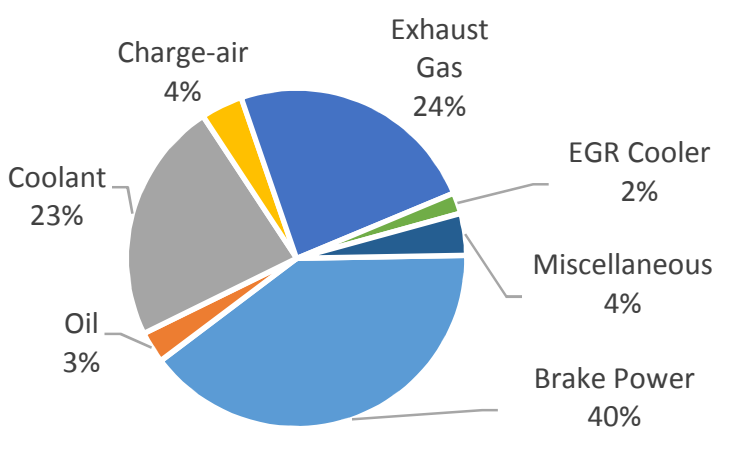

0D/3D Model

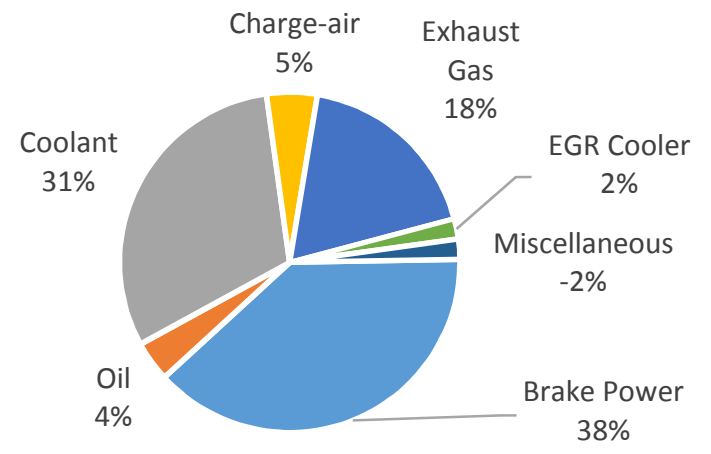

OD Model

Fig. 4 Thermal Energy Balance

\section{CONCLUSIONS}

The integrated simulation method is implemented in vehicle thermal systems of a bus engine. A MATLAB based low-order (OD) model and 3D CFD models using FLUENT have been developed. The OD model considers heat transfer aspects and thermodynamic laws of all the under-hood thermal systems. Through the CFD simulations the heat transfer coefficient of radiator and charge-air cooler is calculated and fed to the low-order model.

As the engine is placed at the rear of the bus, the heat and fluid flow features are difficult to be estimated using full scale $0 \mathrm{D}$ model. Therefore, more accurate results can be generated using the proposed approach. Moreover, parametric study can be carried out in order to reevaluate the thermal energy distribution. 


\section{ACKNOWLEDGMENT}

The authors would like to thank the Engineering and Physical Research Council (EPSRC) and Wrights Group Ltd for funding this project.

\section{REFERENCES}

[1] Department for Business, Energy \& Industrial Strategy, UK Greenhouse Gas Emissions, 2017.

[2] EU Commission, Commission Regulation (EU) No 582/2011 - Heavy Duty, Official Journal of the European Union, vol. L 167 , p. 1, 2011

[3] H. J. Kim and C.J. Kim, "A Numerical Analysis for the Cooling Module Related to Automobile Air-Conditioning System”, Applied Thermal Engineering, vol. 28, no 14-15, pp. 1896-1905, 2008.

[4] G. Wang, Q. Gao, H. Zang and Y. Wang, "A Simulation Approach of under-hood Thermal Management", Advances in Engineering Software, vol. 100, pp. 43-52, 2016.

[5] I. Bayraktar, "Computational Simulation Methods for Vehicle Thermal Management", Applied Thermal Engineering, vol. 36, no 1, pp. 325-329, 2012.

[6] O. Bolehovsky and A.N. Novotny, "Influence of Underhood Flow on Engine Cooling Using 1D and 3D Approach", 2015. 